\title{
Where Does Treatment Optimism Fit in? Examining Factors Associated with Consistent Condom Use Among People Receiving Antiretroviral Treatment in Rio de Janeiro, Brazil
}

\author{
Homaira Hanif • Francisco I. Bastos • \\ Monica Malta $\cdot$ Neilane Bertoni $\cdot$ Peter J. Winch · \\ Deanna Kerrigan
}

Published online: 17 February 2014

(C) Springer Science+Business Media New York 2014

\begin{abstract}
In the era of highly active antiretrovirals, people living with HIV (PLWH) have resumed sexual activity in the context of longer and healthier lives, and thus the chances of transmitting the HIV virus, as well as the potential to be re-infected also increase. HIV treatment optimism has been found to be associated with sexual risk behaviors among PLWH in different settings. A cross sectional survey was conducted to examine the relationship between treatment optimism, safer sex burnout and consistent condom use as well as variables associated with treatment optimism in a sample of PLWH on antiretrovirals (ARVs) in Rio de Janeiro, Brazil $(n=604)$. Seventy-two percent of participants always used a condom in the last 6 months. Homosexual, bisexual, transexual persons were less likely to use condoms consistently than heterosexuals (AOR .58 CI .42-.78). Those who were treatment optimistic (AOR .46 CI .25-.88) were more likely not use a condom consistently in the past 6 months, as were participants who reported safer sex burnout (AOR .58 CI .36-
\end{abstract}

H. Hanif $(\bowtie) \cdot$ P. J. Winch

Social and Behavioral Interventions Program, Department of International Health, Johns Hopkins Bloomberg School of Public Health, Baltimore, MD, USA

e-mail: hhanif@jhsph.edu

F. I. Bastos · N. Bertoni

Department of Health Information, Oswaldo Cruz Foundation, Rio de Janeiro, Brazil

\section{Malta}

Department of DCS/ENSP, Oswaldo Cruz Foundation, Rio de Janeiro, Brazil

D. Kerrigan

Department of Health, Behavior and Society, Johns Hopkins Bloomberg School of Public Health, Baltimore, MD, USA
.90). Sexual orientation, safer sex burnout, and lower education levels were significantly associated with higher treatment optimism in multivariate analysis. Study findings highlight the need to address psychosocial factors such as treatment optimism and safer sex burnout associated with lower consistent condom use among PLWH in Rio de Janeiro, Brazil.

Keywords HIV - Condom use - Treatment optimism . Safe sex burnout $\cdot$ Brazil

\section{Introduction}

The advent of effective antiretroviral therapy (ART) changed the course of the HIV epidemic and gave hope to individuals living with HIV/AIDS. Combination therapy increased survival and decreased morbidity, making HIV/ AIDS more a chronic disease than a death sentence, and allowed the continuation of sexual activity in the lives of people living with HIV (PLWH) [1-5]. With the normal resumption of sexual activity and longer lifespan, the chances of transmitting the HIV virus also increase, as well as the potential to be re-infected. Sexually transmitted infections (STIs) such as syphilis and HIV have risen among men who have sex with men (MSM) in higher income countries [6-10], highlighting the importance of understanding how to promote and maintain sexual protective behaviors.

While having an undetectable viral load as a result of antiretrovirals (ARVs) substantially decreases the likelihood of HIV transmission, sexual activity is not free of risks [11]. The viral load in the blood does not necessarily correlate with the viral load in the semen [12]. Co-infection with another STI can also increase the likelihood of HIV 
transmission due to the increase of viral shedding [13-15]. In addition, mathematical modeling among MSM in the Netherlands [16], Australia [17], and San Francisco [18], as well as among HIV discordant couples in Uganda [19] have shown that HIV treatment benefits at the level of networks and communities may decrease when there is an increase in HIV sexual risk behaviors, such as an increase in sexual partners or unprotected sexual intercourse.

Sexual risk behaviors have been investigated among MSM populations in order to explain the change in STI rates, especially syphilis. While there was a striking decrease in syphilis since the start of the HIV epidemic among MSM, increases in STIs in the late 1990s in developed country settings led researchers to examine psychosocial constructs such as treatment optimism and safer sex burnout to explain the trends [20]. Safer sex burnout relates to the inability or decreased desire or fatigue to maintain protective sexual practices. One study examined safe sex fatigue as a mediator for rectal gonorrhea among MSM and found safe sex fatigue was the only variable associated with infection among HIV positive men [21]. Treatment optimism refers to decreased concern or complacency regarding protective sexual behaviors due to the availability or use of ARVs, creating the perception that HIV is less serious or that transmission is less likely to occur [22]. Studies, mostly of cross sectional design, have shown a significant association between treatment optimism and risk behavior, such as unprotected anal intercourse (UAI) [23-26]. Most of these studies have been conducted in higher income countries and focused on MSM populations.

To date, few studies have addressed the influence of different demographic, psychosocial and structural factors that may influence attitudes related to HIV treatment optimism. Additionally, the vast majority of studies have assessed HIV treatment optimism among MSM living in higher-income countries. Our study benefits from the fact it was carried out in a middle-income country, in a network of public health facilities serving a diverse clientele in terms of age, gender, sexual orientation, race/ethnicity, and socio-economic position. One study with a racially diverse group of MSM across multiple cities in the US did report that those with lower income were more likely to report that HIV is now less transmissible [27]. In the same study, a decrease in the perceived sense of HIV severity was associated with being nonWhite, having an undetectable viral load, and better mental health. A qualitative study in Brazil found that a minority of participants were treatment optimistic, but findings indicated that men may be more likely to be treatment optimistic than women [28]. A review of recent studies on treatment optimism since the introduction of treatment as prevention found support for the association between treatment optimism and sexual risk behaviors, though most of the findings came from MSM populations [29]. Given the growing emphasis on treatment as prevention to stop the spread of the HIV epidemic and associated large-scale rollout of ARVs across settings, treatment optimism in relation to sexual risk behaviors must be examined comprehensively and across diverse populations.

Brazil has offered universal access to ARVs since 1996 and is an important setting to examine the potential role of treatment optimism. While the HIV prevalence in the general population aged $15-49$ has been stable at $0.6 \%$ since 2004 , higher prevalence is found among more vulnerable populations such as drug users, female sex workers and MSM [30]. Guimaraes et al. [31] found approximately a quarter of men living with HIV engaged in unprotected anal or vaginal sex in the previous year. In a previous partner study with HIV positive men, Guimaraes et al. [32] found almost $40 \%$ of couples did not consistently use a condom with their partner in the last year, despite serodiscordance. In addition, unsafe sex increased over time in that study following HIV disclosure, indicating the difficulties in maintaining safer sex practices in couples and signifying the potential for safer sex burnout. A recent study in Brazil found that most pregnant women remained sexually active after learning that they were HIV-positive, but did not know their partner's HIV status nor used condoms consistently [33]. While there is a growing literature on the sexual behavior of PLWH in Brazil including to some extent safe sex burnout, the role of treatment optimism has not been explicitly addressed.

In light of the aforementioned gaps in the literature related to treatment optimism, safer sex burnout and condom use, particularly in a diverse population and middleincome country, the purpose of the current study examined the association between psychosocial factors and consistent condom use. We also examine factors associated with treatment optimism among PLWH currently on ARVs recruited from public health units in Rio de Janeiro, Brazil.

\section{Methods}

Participants and Procedures

This analysis is part of a larger study focusing on the psychosocial and structural factors associated with the sexual health and wellbeing of PLWH/AIDS receiving treatment from public health clinics in Rio de Janeiro. The study recruited 900 participants, of whom 650 were currently on ARVs. This analysis focuses on complete case participants on ARVs $(n=604)$ and specifically those who were sexually active in the last 6 months $(n=446)$ in the case of the consistent condom use analysis.

Eligible participants were at least 18 years of age, had a confirmed HIV-positive status, received HIV treatment and care from a public health clinic, and were willing to provide consent. The participants were recruited from six key 
public health facilities of the total 29 health centers managed by the Rio de Janeiro Health Secretariat. The six clinics were selected based on the number of patients in care and location (geographic and administrative), ensuring a heterogeneous sample representing the range of clinics. These six facilities provide care for approximately $60 \%$ of the over 14,000 patients living with HIV/AIDS under care in the public health system in Rio de Janeiro at the time of the study. The study received ethical approval from the Institutional Review Boards (IRB) of the Johns Hopkins School of Public Health, the Oswaldo Cruz Foundation, the Municipal Health Secretariat, and the National IRB of the Brazilian Ministry of Health.

A pilot test was conducted before survey implementation to ensure clarity of the questionnaire. The survey was conducted from August 2008 through July 2009. A trained supervisor recruited participants in the waiting area of the clinics. The purpose of the survey was explained to potential participants and any questions were answered. After they agreed to participate, the participant was taken to a private room where a trained interviewer went through the consent form and obtained written consent. The questionnaire took approximately $50 \mathrm{~min}$ to complete. Interview responses were recorded on Teleform ${ }^{\circledR}$ scannable data forms and reviewed by the interviewer for completeness and consistency prior to the participant's departure. The forms were scanned for computer entry by the project coordinator.

\section{Measures}

Measures in the survey included sociodemographic variables as well as psychosocial factors including psychological well-being, safer sex burnout and treatment optimism. ARV adherence was also included. The dependent variable, consistent condom use, and measure details are listed below.

\section{Socio-demographic and Background Variables}

Analysis variables included: age, gender, race/ethnicity, education, income, sexual orientation, religion, HIV status of partner, number of sexual partners, and length of time on ARVs.

\section{Psychological Well-Being}

The Hospital Anxiety and Depression Scale (HAD) is a tested tool to measure psychological well-being over the past week, especially for chronic conditions, and has been used in Brazil [34-36]. This scale is composed of 14 questions divided into an anxiety subscale and a depression subscale to identify possible and probable cases of anxiety and depression among non-psychiatric patients. Physical symptoms are not included in this scale (e.g. headaches, insomnia, fatigue). Responses are rated on a four point scale (hardly at all to most of the time) and include items such as: "I felt tense or wound-up;" "I enjoyed the things I use to;" "I had worrying thoughts go through my mind;" "I felt cheerful;" and "I could sit at ease and relax." This study used 11 as the cutoff for possible depression (Cronbach's alpha $=.76$ ) or anxiety (Cronbach's alpha $=.81$ ), respectively [37].

\section{Safer Sex Burnout}

An eight item aggregate measure based on attitudes towards condom use related to condom use fatigue was developed based on the literature and findings from indepth interviews with PLWH in Brazil [28]. Responses were rated on a four point scale [1-4] based on degree of agreement with the following phrases: "I feel tired of using condoms;" "I have given up worrying about whether I use condoms or not;" "I feel as though I've been using condoms forever;" "I often wish for a day when I don't have to worry about condoms anymore;" "Using condoms is becoming exhausting;" "I'm tired of worrying about HIV/ STIs;" "I often feel like I don't have the energy to worry about condoms anymore." The measure ranged from 8 to 32 (out of a possible range of 8-32) with a median score of 24 (mean 23; SD 4.8). A lower score indicated having safer sex burnout. The aggregate measure had a Cronbach's alpha of .70 and was dichotomized at the median for ease of interpretation.

\section{Treatment Optimism}

Treatment optimism was measured through a scale that included 11 of the original items developed by Van de Ven et al. [38] such as: "New HIV treatments take the worry out of sex;" "An HIV positive person on new treatments is unlikely to transmit HIV;" "It's never safe to have sex without a condom, regardless of viral load;" "Until there is a complete cure for HIV/AIDS, prevention is still the best practice." The treatment optimism index ranged from 17 to 44 (out of a possible range of 11-44) with a median score of 38 (mean 37; SD 5.5). A higher score indicated skepticism regarding the statements, therefore not being treatment optimistic. The scale had a Cronbach's alpha of .69 and was dichotomized at the median for ease of interpretation. The dichtomization did not change study results.

\section{ARV Adherence}

A modified AIDS Clinical Trial Group's (ACTG) questionnaire was used to measure medication adherence [39] 
which has been used in previous studies in Brazil [34]. The questions focus on recent adherence to minimize recall bias. The outcome adherence was measured by the question: In the last 4 days, how many days did you take all of your doses of all of your HIV medications? We dichotomized the indicator as adherent if it was 4 days and all other responses as nonadherent.

\section{Consistent Condom Use}

Participants were asked how frequently they used a condom in the last 6 months with responses in a five-point Likert scale ranging from always to never. Answers were dichotomized into always versus anything less.

\section{Analytic Strategy}

Data were analyzed using the statistical software Stata_11 [40]. Descriptive analysis was conducted to examine the distribution of the data such as frequencies, medians, and ranges. Aggregate measures were developed using reliability analysis to assess internal consistency.

Bivariate statistical tests such as $t$ tests (for continuous variables) and Chi square tests (for categorical variables) were utilized to characterize the direction and significance of the relationship between major study variables, as was bivariate logistic regression. All variables found to be significantly associated with the outcome in the bivariate analysis were included in the multivariate analysis, as well nonsignificant variables hypothesized to be confounders or effect modifiers based on findings from previous research or for conceptual purposes. Multivariate logistic regression analysis was conducted to assess the adjusted association between the primary independent variables and dependent variables, e.g. consistent condom use and treatment optimism. All independent variables were assessed for collinearity by examining their correlation coefficients. Individuals who receive services from the same clinic may have more similarities than individuals from the other clinics, creating a potential clustering effect. The variancecovariance estimate (VCE) command was used to adjust for this within clinic intraclass correlation [41, 42].

\section{Results}

Table 1 presents the sociodemographic characteristics for PLWH on ARVs. Participants ranged in age from 19 to 67 years, with a median age of 42 years. Our sample consisted of mostly men $(68 \%)$ of whom $46 \%$ were homosexual and $11 \%$ bi-sexual. Education levels were relatively low given only about $14 \%$ had achieved
Table 1 Sample characteristics among PLWH on ARVs and participants sexually active in the last 6 months attending public clinics in Rio de Janeiro, Brazil $(\mathrm{n}=604)$

\begin{tabular}{|c|c|c|}
\hline Characteristics & $(\mathrm{n}=604)$ & Percentage \\
\hline \multicolumn{3}{|l|}{ Gender } \\
\hline Male & 409 & 68 \\
\hline Female & 189 & 31 \\
\hline Transgender & 6 & 1 \\
\hline \multicolumn{3}{|l|}{ Age $[$ range $=19-67$ years; median $=42]$} \\
\hline $19-35$ & 143 & 24 \\
\hline $36-41$ & 136 & 23 \\
\hline $42-47$ & 168 & 28 \\
\hline $48-67$ & 157 & 26 \\
\hline \multicolumn{3}{|l|}{ Race } \\
\hline White & 157 & 26 \\
\hline $\begin{array}{l}\text { Non-White (Black, Brown, Yellow, } \\
\text { Indigenous) }\end{array}$ & 447 & 74 \\
\hline \multicolumn{3}{|l|}{ Education } \\
\hline Primary or less & 265 & 44 \\
\hline Secondary & 252 & 42 \\
\hline Superior or more & 87 & 14 \\
\hline \multicolumn{3}{|l|}{ Sexual orientation } \\
\hline Heterosexual & 359 & 59 \\
\hline Other (homosexual, bi, trans) & 245 & 41 \\
\hline \multicolumn{3}{|l|}{ Partner status } \\
\hline No partner & 312 & 52 \\
\hline With partner & 292 & 48 \\
\hline \multicolumn{3}{|l|}{ Sexual partners } \\
\hline $0-1$ & 461 & 76 \\
\hline $2+$ & 143 & 24 \\
\hline \multicolumn{3}{|l|}{ Main partner HIV positive } \\
\hline No & 519 & 86 \\
\hline Yes & 85 & 14 \\
\hline \multicolumn{3}{|l|}{ Religion } \\
\hline Catholic & 232 & 38 \\
\hline Evangelical & 158 & 26 \\
\hline Other (Espirita, Afro-Brazilian, Other) & 137 & 23 \\
\hline None & 77 & 13 \\
\hline \multicolumn{3}{|l|}{ Length of time on ARVs (years) } \\
\hline $0-1$ & 141 & 23 \\
\hline $2-6$ & 190 & 31 \\
\hline $7-23$ & 273 & 45 \\
\hline
\end{tabular}

superior level (University level) or more and a median of 11 years. Monthly income ranged from 0 to 4790 USD (mean 530 USD) with the majority in low socio-economic status. Length of time on ARVs ranged from less than 1-23 years, with a median of 6 years.

Approximately $74 \%$ of the participants were sexually active $(\mathrm{n}=446)$ in the previous 6 months. About $24 \%$ $(n=143)$ of participants, mainly men, had two or more 
Table 2 Bivariate and multivariate logistic regression analysis of sociodemographic, psychosocial and treatment variables on consistent condom use (in the last 6 months) among sexually active PLWH in Rio de Janeiro, Brazil $(n=446)$

\begin{tabular}{llll}
\hline$\%$ & UOR $(95 \%$ & AOR $(95 \%$ \\
Yes & CI $)$ & CI $)$ \\
\hline
\end{tabular}

Sociodemographic variables

Sex

Male

Female

$74 \quad 1.00$

1.00

Transgender

$65 \quad .67$

$(.43-1.06) \quad(.32-1.15)$

Age $[$ range $=19-67$ years; median $=42]$

$\begin{array}{lccc}19-35 & 64 & 1.00 & 1.00 \\ 36-41 & 70 & 1.3 & 1.14 \\ & & (.74-2.29) & (.85-1.54) \\ 42-47 & 76 & 1.75 & 1.43 \\ & & (.89-2.69) & (.77-2.67) \\ 48-67 & 77 & 1.83 & 1.60\end{array}$

Race

White

$(1.00-3.35)$

$(.64-3.46)$

$\begin{array}{ll}73 & 1.00 \\ 71 & .92 \\ & (.57-1.48)\end{array}$

Superior or more

Religion

Catholic

Evangelical

Other (Espirita, Afro-

Brazilian, Other)

None

Sexual orientation

Other (homosexual, bi, trans)

1.00

1.10

(.65-1.88)

$70 \quad 1.00$

09

(.69-1.70)

1.00

.98

(.67-1.41)

$75 \quad 1.24$

(.67-2.30)

.90

(.59-1.38)

$41 \quad 1.00$

1.00

$23 \quad .90$

(.52-1.55)

$21 \quad .66$

.98

(.54-1.79)

.68

$(.39-1.12) \quad(.31-1.46)$

$\begin{array}{lll}15 & 1.10 & .82\end{array}$

(.56-2.15) (.26-2.54)

Sexual partners

$0-1$

$2+$

$\begin{array}{ll}72 & 1.00\end{array}$

$71 \quad .97$

(.62-1.51)

1.00

$.58(.42-$

$.78)$

Main partner HIV positive

No

$74 \quad 1.00$

$64 \quad .63$

(.38-1.06)

1.00

.93

(.47-1.86)

Yes

Individual income

\begin{tabular}{lcll} 
Low $(0-374)$ & 66 & 1.00 & 1.00 \\
High $(375-4,790)$ & 77 & 1.76 & 1.49 \\
& & $(1.16-2.66)$ & $(.94-2.36)$ \\
\hline
\end{tabular}

Table 2 continued

\begin{tabular}{|c|c|c|c|}
\hline & $\begin{array}{l}\% \\
\text { Yes }\end{array}$ & $\begin{array}{l}\text { UOR }(95 \% \\
\text { CI) }\end{array}$ & $\begin{array}{l}\text { AOR }(95 \% \\
\text { CI })\end{array}$ \\
\hline \multicolumn{4}{|c|}{ Psychosocial variables } \\
\hline \multicolumn{4}{|l|}{ Treatment optimism } \\
\hline Low & 80 & 1.00 & 1.00 \\
\hline High & 63 & $.44(.29-.66)$ & $\begin{array}{l}.46(.25- \\
.88)\end{array}$ \\
\hline \multicolumn{4}{|l|}{ Safer sex burn out } \\
\hline Low & 79 & 1.00 & 1.00 \\
\hline High & 65 & $.49(.32-.75)$ & $\begin{array}{l}.58(.36- \\
.93)\end{array}$ \\
\hline \multicolumn{4}{|l|}{ Depression } \\
\hline No $(<11)$ & 70 & 1.00 & 1.00 \\
\hline Depressed $(>11)$ & 73 & $\begin{array}{l}1.15 \\
\quad(.73-1.80)\end{array}$ & $\begin{array}{l}1.14 \\
\quad(.62-2.10)\end{array}$ \\
\hline \multicolumn{4}{|l|}{ Anxiety } \\
\hline No $(<11)$ & 75 & 1.00 & 1.00 \\
\hline Anxiety (>11) & 65 & $.62(.40-.95)$ & $\begin{array}{l}1.15 \\
(.64-2.06)\end{array}$ \\
\hline \multicolumn{4}{|l|}{ Treatment variables } \\
\hline \multicolumn{4}{|c|}{ Length of time on ARVs (years) } \\
\hline $0-1$ & 69 & 1.00 & 1.00 \\
\hline $2-6$ & 71 & $\begin{array}{l}1.06 \\
(.61-1.84)\end{array}$ & $\begin{array}{l}1.04 \\
\quad(.68-1.59)\end{array}$ \\
\hline $7-23$ & 75 & $\begin{array}{l}1.32 \\
(.80-2.19)\end{array}$ & $\begin{array}{l}1.08 \\
(.63-1.84)\end{array}$ \\
\hline \multicolumn{4}{|l|}{ Adherence } \\
\hline No & 60 & 1.00 & 1.00 \\
\hline Yes & 74 & $\begin{array}{l}1.91 \\
\quad(1.14-3.20)\end{array}$ & $\begin{array}{l}1.50 \\
(.63-3.57)\end{array}$ \\
\hline
\end{tabular}

$\overline{U O R}$ unadjusted odds ratio, $C I$ confidence interval, $A O R$ adjusted odds ratio

sexual partners in the last 6 months. About $27 \%$ $(\mathrm{n}=166)$ of participants were not sexually active in the previous 6 months, and $41 \%(\mathrm{n}=77)$ of women did not have a sexual partner in the last 6 months versus $22 \%$ $(\mathrm{n}=89)$ of men. For those who were sexually active, approximately $60 \%(\mathrm{n}=340)$ had sexual intercourse at least once a week or more. The bivariate and multivariate results will be discussed separately for consistent condom use and treatment optimism.

\section{Consistent Condom Use}

Seventy-two percent $(n=320)$ of sexually active respondents always used a condom in the previous 6 months. The main reasons reported by participants for not using a condom were that it could compromise men's pleasure $(\mathrm{n}=67)$ and that it was not romantic $(\mathrm{n}=37)$. Table 2 presents the bivariate and multivariate regression results 
Table 3 Bivariate and multivariate logistic regression analysis of sociodemographic, psychosocial and treatment variables on treatment optimism among PLWH in Rio de Janeiro, Brazil $(\mathrm{n}=604)$

\begin{tabular}{|c|c|c|c|c|c|}
\hline & $\begin{array}{l}\% \\
\text { Yes }\end{array}$ & UOR & $(95 \% \mathrm{CI})$ & AOR & $(95 \% \mathrm{CI})$ \\
\hline \multicolumn{6}{|c|}{ Sociodemographic variables } \\
\hline \multicolumn{6}{|c|}{ Gender } \\
\hline Male & 45 & 1.00 & & 1.00 & \\
\hline Female & 51 & 1.30 & $(.92-1.84)$ & 1.41 & $(.97-2.06)$ \\
\hline Transgender & 50 & 1.23 & $(.25-6.19)$ & .93 & $(.33-2.60)$ \\
\hline \multicolumn{6}{|c|}{ Age $[$ range $=19-67$ years; median $=42]$} \\
\hline $19-35$ & 43 & 1.00 & & 1.00 & \\
\hline $36-41$ & 46 & 1.16 & $(.72-1.86)$ & 1.34 & $(.74-2.43)$ \\
\hline $42-47$ & 49 & 1.31 & $(.84-2.06)$ & 1.79 & $(1.02-3.15)$ \\
\hline $48-67$ & 48 & 1.26 & $(.80-1.99)$ & 1.73 & $(1.02-2.95)$ \\
\hline \multicolumn{6}{|l|}{ Race } \\
\hline White & 45 & 1.00 & & 1.00 & \\
\hline $\begin{array}{l}\text { Non-White (Black, } \\
\text { Brown, Yellow, } \\
\text { Indigenous) }\end{array}$ & 48 & 1.13 & $(.79-1.63)$ & .97 & $(.65-1.46)$ \\
\hline \multicolumn{6}{|l|}{ Education } \\
\hline Primary or less & 54 & 1.00 & & 1.00 & \\
\hline Secondary & 45 & .70 & $(.50-.99)$ & .84 & $(.58-1.22)$ \\
\hline Superior or more & 32 & .41 & $(.25-.68)$ & .50 & $(.26-.97)$ \\
\hline \multicolumn{6}{|l|}{ Religion } \\
\hline Catholic & 50 & 1.00 & & 1.00 & \\
\hline Evangelical & 53 & 1.12 & $(.74-1.67)$ & 1.22 & $(.65-2.29)$ \\
\hline $\begin{array}{l}\text { Other (Espirita, } \\
\text { Afro-Brazilian, } \\
\text { other) }\end{array}$ & 43 & .74 & $(.49-1.14)$ & .79 & $(.49-1.26)$ \\
\hline None & 30 & .42 & $(24-.73)$ & .46 & $(.23-.91)$ \\
\hline \multicolumn{6}{|l|}{ Sexual orientation } \\
\hline Heterosexual & 48 & 1.00 & & 1.00 & \\
\hline $\begin{array}{l}\text { Other (homosexual, } \\
\text { bi, trans) }\end{array}$ & 45 & .90 & $(.65-1.25)$ & 1.65 & $(1.18-2.29)$ \\
\hline \multicolumn{6}{|l|}{ Sexual partners } \\
\hline $0-1$ & 46 & 1.00 & & 1.00 & \\
\hline $2+$ & 49 & 1.12 & $(.77-1.63)$ & 1.32 & $(.86-2.02)$ \\
\hline \multicolumn{6}{|l|}{ Individual income } \\
\hline Low (0-374) & 52 & 1.00 & & 1.00 & \\
\hline High $(375-4,790)$ & 42 & .67 & $(.49-.93)$ & .85 & $(.57-1.26)$ \\
\hline \multicolumn{6}{|l|}{ Psychosocial variables } \\
\hline \multicolumn{6}{|l|}{ Safer sex burn out } \\
\hline Low & 37 & 1.00 & & 1.00 & \\
\hline High & 57 & 2.22 & $(1.61-3.08)$ & 2.18 & $(1.35-3.51)$ \\
\hline \multicolumn{6}{|l|}{ Depression } \\
\hline No $(<11)$ & 54 & 1.00 & & 1.00 & \\
\hline Depressed (>11) & 44 & .66 & $(.46-.93)$ & .73 & $(.54-.98)$ \\
\hline \multicolumn{6}{|l|}{ Anxiety } \\
\hline No $(<11)$ & 46 & 1.00 & & 1.00 & \\
\hline Anxiety (>11) & 48 & 1.05 & $(.75-1.47)$ & .90 & $(.63-1.29)$ \\
\hline
\end{tabular}

Table 3 continued

$\begin{array}{llllll}\% & \text { UOR } & (95 \% & \mathrm{CI}) & \text { AOR } & (95 \% \mathrm{CI}) \\ \text { Yes } & & \end{array}$

\begin{tabular}{|c|c|c|c|c|c|}
\hline \multicolumn{6}{|c|}{ Treatment variables } \\
\hline \multicolumn{6}{|c|}{ Length of time on ARVs (years) } \\
\hline $0-1$ & 53 & 1.00 & & 1.00 & \\
\hline $2-6$ & 53 & .99 & $(.65-1.55)$ & .98 & $(.51-1.88)$ \\
\hline $7-23$ & 39 & .57 & $(.38-.86)$ & .52 & $(.28-.99)$ \\
\hline \multicolumn{6}{|c|}{ Adherence } \\
\hline No & 51 & 1.00 & & 1.00 & \\
\hline Yes & 46 & .82 & $(.54-1.25)$ & .83 & $(.60-1.13)$ \\
\hline
\end{tabular}

$U O R$ unadjusted odds ratio, $C I$ confidence interval, $A O R$ adjusted odds ratio

regarding sociodemographic and psychosocial factors associated with consistent condom use. Of the sociodemographic variables in the bivariate analysis, being older (more than 47 years) and having higher income were significantly associated with consistent condom use $(p<.05)$. All of the psychosocial variables assessed were significantly associated with consistent condom use in the bivariate analysis (treatment optimism, safer sex burnout and anxiety), except for depression. Being adherent to their ARV medications was significantly associated with consistent condom use in the bivariate analysis.

In the multivariate analysis, homosexual, bisexual, transexual persons were less consistent condom users than heterosexuals (AOR .58 [.42-.78]). Those with higher treatment optimism were significantly negatively associated with consistent condom use in the past 6 months (AOR .46 [.25-.88]). Those who experienced safer sex burnout were also less likely to consistently use condoms in the past 6 months (AOR .58 [.36-.9]). Older age, having anxiety and being adherent to ARV medications were no longer significantly associated in the multivariate model. We also tested the interaction between treatment optimism and safer sex burnout and found that it was not statistically associated with consistent condom use in the multivariate model.

\section{Treatment Optimism}

Table 3 presents the bivariate and multivariate regression results regarding factors associated with higher treatment optimism. Of the sociodemographic variables in the bivariate analysis, higher education, having no religious affiliation, higher income, and 7 or more years on ARVs were significantly associated with treatment optimism $(p<.05)$. Of the psychosocial measures, safer sex burnout and depression were significantly associated with treatment 
optimsim. Treatment optimism and safer sex burnout were significantly correlated (Pearson's r $.30 p<.0001$ ).

In the multivariate analysis, older age was significantly associated with being treatment optimistic with those 42 years and older being more treatment optimistic than the reference group of 19-35 years old (42-47 years AOR 1.79 [1.02-3.15] and 48 years plus AOR 1.73 [1.02-2.95]). Sexual orientation became significant with those identifying themselves as homosexual, bisexual, and transexual persons more likely to be associated with higher treatment optimism than heterosexuals (AOR 1.65 [1.18-2.2]). Higher education was significantly associated with lower treatment optimism (AOR .50 [.26-.97]). Those who did not have a religious affiliation were less likely to be treatment optimistic than Catholics (AOR .46 [.23-.91]). Those who have been on ARV for more than 7 years were almost half as likely to be treatment optimistic than participants in their first year of therapy (AOR .52 [.28-.99]). Of the psychosocial variables, participants who were experiencing safer sex burnout were more likely to be treatment optimistic (AOR 2.18 [1.35-3.51]). Participants who were depressed were $25 \%$ less likely to be treatment optimistic than those who were not (AOR .73 [.54-.98]). Adherence was not significantly associated with treatment optimism (AOR .83 [.60-1.13]).

\section{Discussion}

We found that almost three quarters of the respondents reported practicing consistent condom use in the previous 6 months, similar to findings from another study in Brazil [31]. Significant factors associated with inconsistent condom use in this analysis were treatment optimism, safer sex burnout and sexual orientation. Most of the participants were more treatment realistic than treatment optimistic, as others have noted this has developed over time since the introduction of ARVs [25]. This corroborates the findings of Van de Ven and other's that suggests most PLWH are not treatment optimistic [28, 43, 44]. However, findings from other studies suggest that among those who are treatment optimistic, condom use is significantly lower [23, 45], as found here. A recent systematic review also found that being on ARVs or having a reduced viral load was not associated with unprotected sex, but those who believed that ARVs or a reduced viral load reduced HIV transmission did have more sexual risk practices [46].

Treatment optimism and safer sex burnout were also found to be significantly correlated. This is consistent with other literature suggesting optimism might be a post hoc psychological rationalization for safer sex burnout. For example, a longitudinal study found UAI predicted later treatment optimism, but the reverse was not true [47]. These findings, especially the relationship between safer sex burnout and treatment optimism suggest the need for educational messages tailored to vulnerable groups such as MSM regarding the ongoing important of condom use even in the context of being on treatment. It is also important to note that within this study we developed a reliable aggregate measure for safer sex burnout that could be used in future studies concerning sexual behavior among PLWH in Brazil and globally.

The study also documented that those who were older were more likely to be treatment optimistic in this setting. This finding is not consistent with the argument younger people might be more treatment optimistic because they have not lived through the early days of the AIDS epidemic and did not witness close friends dying from AIDS [48]. This finding merits further exploration within the specific socio-political and cultural context of Brazil and its response to HIV, to better understand the potential social dynamics regarding age and HIV treatment optimism.

Participants who had been on ARVs for longer were less likely to be treatment optimistic. It is likely that those who have been on treatment for some time have experienced the difficulties of adherence and potentially have experienced side effects and other set backs, like drug resistance, and may also be more knowledgeable about how ARVs work. In addition, religious affiliation was significantly associated with treatment optimism, with those who did not identify any religious affiliation were less likely to be treatment optimistic than Catholics. It may be that religious affiliation is a marker for other attitudes or behaviors and in turn this finding warrants further research, especially in Brazil where religious institutions have played a key role in the response to the HIV epidemic [49].

Sexual orientation was also significantly associated with lower consistent condom use and higher treatment optimism while controlling for factors such as number of sexual partners, indicating the importance of further research on these issues. Prior research has examined the possibility that MSM have utilized other safer sex practices as alternative strategies to condom use, which could potentially explain the lower rates of condom use observed here [50]. The term "seroadaptive behaviors" is used as an umbrella term to cover the different types and levels of risk reduction practiced by MSM such as serosorting (having sex with only other HIV positives) or strategic positioning (HIV positive partner being in the receptive rather than insertive position) [51]. A survey in San Francisco with MSM found that seroadaptive behaviors were more common than consistent condom use or on the other end of the spectrum of risk behaviors, such as insertive UAI with an 
unknown or HIV negative partner, by HIV positive MSM [51]. The main limitation with describing these categories of risk is that intention was not measured. Therefore while these seroadaptive behaviors are documented, it is not clear how it is conceptualized by MSM, whether they are truly seen as HIV risk reduction or not. Further research is warranted to examine if the lower rates of consistent condom use reported among MSM in this study might be due to these seroadaptive behaviors.

While not statistically significant in the multivariate analysis, it is important to note that participants adherent to ARVs had greater consistent condom use, where $74 \%$ of respondents adherent to their medications were also consistent condom users. Adherence was found to be significantly associated with consistent condom use in the bivariate analysis, but it was not significantly associated with treatment optimism. A longitudinal study also found participants who were treatment optimistic were less likely to be adherent to their HIV medications. This gives credibility to the theory that treatment optimism is rationalization for high risk behavior, since one would assume that those who believed in the efficacy of ARVs would also then be adherent [47]. Other studies have found a significant association with low adherence to ARVs and sexual risk behaviors [52-54]. It is possible that this association is stronger among homogenous populations (e.g. MSM only, adolescents etc.) than our more demographically heterogeneous population in Brazil.

Psychological distress is prevalent among people living with chronic health conditions, especially one such as HIV that greatly impacts intimate relationships [55]. Mental health has been associated with sexual risk behavior, but mostly in developed countries among youth populations [56, 57] or examined within severe mentally ill patients [58]. One prospective cohort study in South Africa found that depressed men were less likely to have used a condom and less likely to report correct condom use at last intercourse [59]. Kerrigan et al. [28] examined the role of treatment optimism on sexual behavior in Rio de Janeiro and found psychosocial factors, such as social validation, to be a key component to participants' sexual behavior, with fear and anxiety surrounding condom use and disclosure in their sexual relationships. This study found participants who were anxious were almost $40 \%$ less likely to have reported using a condom consistently in the last 6 months; though this relationship was no longer significant in the multivariate analysis. We also found depression to be significantly associated with a lower level of treatment optimism. The sheer prevalence of depression (70\%) and anxiety (35\%) among the participants warrants further research, especially in relation to its potential relationship to safer sex burnout and treatment optimism.
Limitations

The main limitation of this study is its cross-sectional design, which only allows us to determine association and not causation. In addition, we have a convenience sample of PLWH and therefore the results might not be generalizable outside of Rio de Janeiro, Brazil. We also collected self-reported data, which may have been subject to underestimation due to social desirability bias, especially when dealing with sensitive questions concerning sexual behaviors.

\section{Conclusion}

Study findings highlight the need to address psychosocial factors such as treatment optimism and safer sex burnout, which were associated with lower consistent condom use among PLWH, especially in light of the expansion of treatment as prevention strategies. MSM in this setting reported lower condom use and treatment optimism. Future research should examine barriers to condom use among MSM in this context to more effectively address their increased HIV/STI risk.

Acknowledgements We thank the patients in Rio de Janeiro for their participation in this study and acknowledge The Rio Collaborative Group: Betina Durovni \& Rosa Domingues (Municipal Secretariat of Health); Louise Schilkowsky, Lia Adler Cherman, Rosane Messias da Silva, Paulo Roberto N. dos Santos, Naja da Silva Reis, Maria Isabel F. Lima (on behalf of the network of health units); Thais Garcia \& Diego Pacheco (field coordinators) and participating clinicians and staff at the study clinics. The study was funded by the Ford Foundation, Brazil office.

\section{References}

1. Weidle PJ, Holmberg SD, DeCock KM. Changes in HIV and AIDS epidemiology from new generation antiretroviral therapy. AIDS. 1999;13(Suppl A):S61-8.

2. Lee TS, Liang JN, Michaels L, Wright A. The epidermoid formation and its affinity to congenital cholesteatoma. Clin Otolaryngol Allied Sci. 1998;23(5):449-54.

3. Hogg RS, Heath KV, Yip B, Craib KJ, O'Shaughnessy MV, Schechter MT, et al. Improved survival among HIV-infected individuals following initiation of antiretroviral therapy. JAMA. 1998;279(6):450-4.

4. Palella FJ Jr, Delaney KM, Moorman AC, Loveless MO, Fuhrer $\mathrm{J}$, Satten GA, et al. Declining morbidity and mortality among patients with advanced human immunodeficiency virus infection. HIV outpatient study investigators. N Engl J Med. 1998; 338(13):853-60.

5. May MT, Ingle SM. Life expectancy of HIV-positive adults: a review. Sex Health. 2011;8(4):526-33.

6. van Kesteren NM, Hospers HJ, Kok G. Sexual risk behavior among HIV-positive men who have sex with men: a literature review. Patient Educ Couns. 2007;65(1):5-20. 
7. Elford J, Bolding G, Davis M, Sherr L, Hart G. Trends in sexual behaviour among London homosexual men 1998-2003: implications for HIV prevention and sexual health promotion. Sex Transm Infect. 2004;80(6):451-4.

8. Chen SY, Gibson S, Katz MH, Klausner JD, Dilley JW, Schwarcz SK, et al. Continuing increases in sexual risk behavior and sexually transmitted diseases among men who have sex with men: San Francisco, CA, USA 1999-2001. Am J Public Health. 2002;92(9):1387-8.

9. Katz MH, Schwarcz SK, Kellogg TA, Klausner JD, Dilley JW, Gibson S, et al. Impact of highly active antiretroviral treatment on HIV seroincidence among men who have sex with men: San Francisco. Am J Public Health. 2002;92(3):388-94.

10. Stolte IG, Dukers NH, de Wit JB, Fennema JS, Coutinho RA. Increase in sexually transmitted infections among homosexual men in Amsterdam in relation to HAART. Sex Transm Infect. 2001;77(3):184-6.

11. Taylor S, Davies S. Antiretroviral drug concentrations in the male and female genital tract: implications for the sexual transmission of HIV. Curr Opin HIV AIDS. 2010;5(4):335-43.

12. Cohen MS, Hosseinipour M, Kashuba A, Butera S. Use of antiretroviral drugs to prevent sexual transmission of HIV. Curr Clin Top Infect Dis. 2002;22:214-51.

13. Cohen. HIV and sexually transmitted diseases: lethal synergy. Top HIV Med. 2004;12(4):104-7.

14. Kalichman SC, Pellowski J, Turner C. Prevalence of sexually transmitted co-infections in people living with HIV/AIDS: systematic review with implications for using HIV treatments for prevention. Sex Transm Infect. 2011;87(3):183-90.

15. Kalichman SC, Di Berto G, Eaton L. Human immunodeficiency virus viral load in blood plasma and semen: review and implications of empirical findings. Sex Transm Dis. 2008;35(1):55-60.

16. Bezemer D, de Wolf F, Boerlijst MC, van Sighem A, Hollingsworth TD, Prins M, et al. A resurgent HIV-1 epidemic among men who have sex with men in the era of potent antiretroviral therapy. AIDS. 2008;22(9):1071-7.

17. Law MG, Prestage G, Grulich A, Van de Ven P, Kippax S. Modelling the effect of combination antiretroviral treatments on HIV incidence. AIDS. 2001;15(10):1287-94.

18. Blower SM, Gershengorn HB, Grant RM. A tale of two futures: HIV and antiretroviral therapy in San Francisco. Science. 2000;287(5453):650-4.

19. Gray RH, Li X, Wawer MJ, Gange SJ, Serwadda D, Sewankambo NK, et al. Stochastic simulation of the impact of antiretroviral therapy and HIV vaccines on HIV transmission; Rakai, Uganda. AIDS. 2003;17(13):1941-51.

20. Rowniak S. Safe sex fatigue, treatment optimism, and serosorting: new challenges to HIV prevention among men who have sex with men. J Assoc Nurses AIDS Care. 2009;20(1):31-8.

21. Stolte IG, de Wit JB, Kolader M, Fennema H, Coutinho RA, Dukers NH. Association between 'safer sex fatigue' and rectal gonorrhea is mediated by unsafe sex with casual partners among HIV-positive homosexual men. Sex Transm Dis. 2006;33(4):201-8.

22. International Collaboration on HIV Optimism. HIV treatments optimism among gay men: an international perspective. J Acquir Immune Defic Syndr. 2003;32(5):545-50.

23. DE Ostrow, Fox KJ, Chmiel JS, Silvestre A, Visscher BR, Vanable PA, et al. Attitudes towards highly active antiretroviral therapy are associated with sexual risk taking among HIVinfected and uninfected homosexual men. AIDS. 2002;16(5): $775-80$.

24. Van de Ven P, Prestage G, Crawford J, Grulich A, Kippax S. Sexual risk behaviour increases and is associted with HIV optimism among HIV-negative and HIV-positive gay men in Sydney over the 4 year period to February 2000. AIDS. 2000;14(18):2951-3.
25. Kalichman SC, Eaton L, Cain D, Cherry C, Fuhrel A, Kaufman $\mathrm{M}$, et al. Changes in HIV treatment beliefs and sexual risk behaviors among gay and bisexual men, 1997-2005. Health Psychol. 2007;26(5):650-6.

26. Kalichman SC, Nachimson D, Cherry C, Williams E. AIDS treatment advances and behavioral prevention setbacks: preliminary assessment of reduced perceived threat of HIV-AIDS. Health Psychol. 1998;17(6):546-50.

27. Brennan DJ, Welles SL, Miner MH, Ross MW, Rosser BR. HIV treatment optimism and unsafe anal intercourse among HIVpositive men who have sex with men: findings from the positive connections study. AIDS Educ Prev. 2010;22(2):126-37.

28. Kerrigan D, Bastos FI, Malta M, Carneiro-da-Cunha C, Pilotto $\mathrm{JH}$, Strathdee SA. The search for social validation and the sexual behavior of people living with HIV in Rio de Janeiro, Brazil: understanding the role of treatment optimism in context. Soc Sci Med. 2006;62(10):2386-96.

29. Chen Y. Treatment-related optimistic beliefs and risk of HIV transmission: a review of recent findings (2009-2012) in an era of treatment as prevention. Curr HIV/AIDS Rep. 2013;10(1):79-88.

30. Malta M, Magnanini MM, Mello MB, Pascom AR, Linhares Y, Bastos FI. HIV prevalence among female sex workers, drug users and men who have sex with men in Brazil: a systematic review and meta-analysis. BMC Public Health. 2010;10:317.

31. Guimaraes MD, Grinsztejn B, Chin-Hong PV, Campos LN, Gomes VR, Melo VH, et al. Behavior surveillance: prevalence and factors associated with high-risk sexual behavior among HIV-infected men in Brazil in the post-HAART era. AIDS Behav. 2008;12(5):741-7.

32. Guimaraes MD, Boschi-Pinto C, Castilho EA. Safe sexual behaviour among female partners of HIV-infected men in Rio de Janeiro, Brazil. Int J STD AIDS. 2001;12(5):334-41.

33. Yeganeh N, Varella I, Santos BR, Goncalves de Melo M, Simon M, Melo T, et al. Risk-taking behavior for HIV acquisition during pregnancy in Porto Alegre, Brazil. Infect Dis Obstet Gynecol. 2012;2012:490686.

34. Remien RH, Bastos FI, Jnr VT, Raxach JC, Pinto RM, Parker $\mathrm{RG}$, et al. Adherence to antiretroviral therapy in a context of universal access, Rio de Janeiro, Brazil. AIDS Care. 2007;19(6): $740-8$.

35. Zigmond AS, Snaith RP. The hospital anxiety and depression scale. Acta Psychiatr Scand. 1983;67(6):361-70.

36. Campos LN, Guimaraes MD, Remien RH. Anxiety and depression symptoms as risk factors for non-adherence to antiretroviral therapy in Brazil. AIDS Behav. 2010;14(2):289-99.

37. Dagnan D, Chadwick P, Trower P. Psychometric properties of the hospital anxiety and depression scale with a population of members of a depression self-help group. Br J Med Psychol. 2000;73(Pt 1):129-37.

38. Van de Ven P, Crawford J, Kippax S, Knox S, Prestage G. A scale of optimism-scepticism in the context of HIV treatments. AIDS Care. 2000;12(2):171-6.

39. Chesney MA, Ickovics JR, Chambers DB, Gifford AL, Neidig J, Zwick DBB. Self-reported adherence to antiretroviral medications among participants in HIV clinical trials: the AACTG adherence instruments. AIDS Care. 2000;12(3):255-66.

40. StataCorp. Stata Statistical Software: Release 11. College Station: StataCorp LP; 2009.

41. Rogers W. sg17: regression standard errors in clustered samples. Stata Tech Bull. 1993;13:19-23.

42. Williams RL. A note on robust variance estimation for clustercorrelated data. Biometrics. 2000;56:645-6.

43. Van de Ven P, Kippax S, Knox S, Prestage G, Crawford J. HIV treatments optimism and sexual behaviour among gay men in Sydney and Melbourne. AIDS. 1999;13(16):2289-94. 
44. Remien RH, Halkitis PN, O'Leary A, Wolitski RJ, Gomez CA. Risk Perception and sexual risk behaviors among HIV-positive men on antiretroviral therapy. AIDS Behav. 2005;9(2):167-76.

45. Dukers NH, Goudsmit J, de Wit JB, Prins M, Weverling GJ, Coutinho RA. Sexual risk behaviour relates to the virological and immunological improvements during highly active antiretroviral therapy in HIV-1 infection. AIDS. 2001;15(3):369-78.

46. Crepaz N, Hart TA, Marks G. Highly active antiretroviral therapy and sexual risk behavior: a meta-analytic review. JAMA. 2004; 292(2):224-36.

47. Huebner DM, Rebchook GM, Kegeles SM. A longitudinal study of the association between treatment optimism and sexual risk behavior in young adult gay and bisexual men. J Acquir Immune Defic Syndr. 2004;37(4):1514-9.

48. Ostrow DG, Silverberg MJ, Cook RL, Chmiel JS, Johnson L, Li $\mathrm{X}$, et al. Prospective study of attitudinal and relationship predictors of sexual risk in the multicenter AIDS cohort study. AIDS Behav. 2008;12(1):127-38.

49. Murray LR, Garcia J, Munoz-Laboy M, Parker RG. Strange bedfellows: the Catholic Church and Brazilian National AIDS Program in the response to HIV/AIDS in Brazil. Soc Sci Med. 2011;72(6):945-52.

50. Hart GJ, Elford J. Sexual risk behaviour of men who have sex with men: emerging patterns and new challenges. Curr Opin Infect Dis. 2010;23(1):39-44.

51. Snowden JM, Raymond HF, McFarland W. Prevalence of seroadaptive behaviours of men who have sex with men, San Francisco, 2004. Sex Transm Infect. 2009;85(6):469-76.
52. Kalichman SC, Cherry C, Amaral CM, Swetzes C, Eaton L, Macy R, et al. Adherence to antiretroviral therapy and HIV transmission risks: implications for test-and-treat approaches to HIV prevention. AIDS Patient Care STDS. 2010;24(5):271-7.

53. Joseph HA, Flores SA, Parsons JT, Purcell DW. Beliefs about transmission risk and vulnerability, treatment adherence, and sexual risk behavior among a sample of HIV-positive men who have sex with men. AIDS Care. 2010;22(1):29-39.

54. Flaks RC, Burman WJ, Gourley PJ, Rietmeijer CA, Cohn DL. HIV transmission risk behavior and its relation to antiretroviral treatment adherence. Sex Transm Dis. 2003;30(5):399-404.

55. Siegel K, Lekas HM. AIDS as a chronic illness: psychosocial implications. AIDS. 2002;16(Suppl 4):S69-76.

56. Ramrakha S, Caspi A, Dickson N, Moffitt TE, Paul C. Psychiatric disorders and risky sexual behaviour in young adulthood: cross sectional study in birth cohort. BMJ. 2000;321(7256):263-6.

57. Parsons JT, Halkitis PN, Wolitski RJ, Gomez CA. Correlates of sexual risk behaviors among HIV-positive men who have sex with men. AIDS Educ Prev. 2003;15(5):383-400.

58. Guimaraes MD, McKinnon K, Campos LN, Melo AP, Wainberg M. HIV risk behavior of psychiatric patients with mental illness: a sample of Brazilian patients. Rev Bras Psiquiatr. 2010;32(4): 351-60.

59. Nduna M, Jewkes RK, Dunkle KL, Shai NP, Colman I. Associations between depressive symptoms, sexual behaviour and relationship characteristics: a prospective cohort study of young women and men in the Eastern Cape, South Africa. J Int AIDS Soc. 2010;13:44. 